\title{
Synergistic effects of vemurafenib and fingolimod (FTY720) in vemurafenib-resistant melanoma cell lines
}

\author{
TOMOKO TAKAHASHI, NAOKO ABE, HIROYUKI KANOH, YOSHIKO BANNO and MARIKO SEISHIMA \\ Department of Dermatology, Gifu University Graduate School of Medicine, Gifu 501-1194, Japan
}

Received May 15, 2018; Accepted September 27, 2018

DOI: $10.3892 / \mathrm{mmr} .2018 .9537$

\begin{abstract}
Vemurafenib, a selective inhibitor of mutated BRAF, is used to treat late-stage melanoma. However, resistance to vemurafenib is urgently required as it can have fatal consequences. Fingolimod (FTY720), a sphingosine-1-phosphate receptor modulator, has been used for the treatment of several malignant neoplasms in clinical trials. The present study investigated the effects of FTY720 and vemurafenib combination treatment on cell death induction, and defined the molecular mechanisms in vemurafenib-resistant melanoma cells. The combination treatment with FTY720 and vemurafenib reduced cell viability, and the expression of apoptosis-associated cleaved poly (adenosine diphosphate-ribose) polymerase (PARP) was increased when compared with treatment with vemurafenib alone in WM-115 cells, a vemurafenib-resistant human melanoma cell line. In addition, the protein expression of phosphorylated extracellular signal-related kinase (ERK) in WM-115 cells was decreased by this combination treatment. Vemurafenib-resistant SK-Mel-28 cells (R-SK-Mel) were established by culturing SK-Mel-28 cells, which are the most sensitive to vemurafenib, in the presence of vemurafenib. Similar to WM-155 cells, the viability of R-SK-Mel cells was reduced and the expression of cleaved PARP was increased by the combination treatment with FTY720 and vemurafenib. In addition, the expression of phosphorylated ERK and Akt was also reduced by this treatment. These results suggested that FTY720 and vemurafenib synergistically induced cell death by downregulating proliferation and survival signalling pathways in vemurafenib-resistant melanoma cells.
\end{abstract}

\section{Introduction}

Numerous anticancer drugs have been used for cancer chemotherapy, but safer and more effective molecular targeted

Correspondence to: Dr Tomoko Takahashi, Department of Dermatology, Gifu University Graduate School of Medicine, 1-1 Yanagido, Gifu 501-1194, Japan

E-mail: tomoko771009@yahoo.co.jp

Key words: vemurafenib, fingolimod, melanoma, apoptosis, cell signaling anticancer agents are needed. In the last decade, immune checkpoint inhibitors and target therapies have been important and effective therapies for many intractable malignant neoplasms including progressive malignant melanoma. In 2002 , it was demonstrated that oncogenic $B R A F$ mutations, predominantly at codon 600 , are in approximately $70 \%$ of cutaneous melanomas (1). The most common $B R A F$ mutations are V600E or V600K $(2,3)$. These mutations lead to constitutive activation of the mitogen-activated protein kinase (MAPK) pathway and increased extracellular signal-related kinase (ERK) activation, which drive the growth and differentiation of malignant cells (4). BRAF inhibitors, such as vemurafenib or dabrafenib, efficiently inhibit ERK activation and tumour proliferation, which rapidly respond after the onset of therapies $(5,6)$. However, unfortunately, responses to BRAF inhibitors are short-lived, with evidence of disease progression within 6-8 months after the beginning of therapy (7). To reduce resistance to BRAF inhibitors, several combinatorial treatments using mitogen-activated protein kinase kinase (MEK) inhibitors (8) or phosphoinositide 3-kinase (PI3K) inhibitors (9) have proven effective. In particular, the MEK inhibitor, trametinib, has been clinically used with dabrafenib as a combination therapy. However, more effective methods to treat BRAF inhibitor-resistant melanomas are needed.

Sphingolipids are the main components of lipid rafts and have crucial functions as signalling molecules. Sphingosine 1-phosphate (S1P) and ceramide regulate proliferation and apoptosis (10-13). In response to various stimuli, ceramide mediates cell death and apoptosis, whereas S1P abrogates apoptosis and mediates cell proliferation and migration (14). Sphingosine kinase (SK) is the key enzyme responsible for converting sphingosine to S1P. Signalling pathways via the S1P receptor contribute to cancer cell survival and proliferation (15), apoptosis reduction (16), and oncogenic transformation (17). Various cancer cells have high levels of SK1 expression/activity, resulting in their enhanced resistance to anticancer agents such as anthracyclines, doxorubicin, and camptothecin $(18,19)$. Thus, SK1 may play an important role in the development and proliferation of cancers such as melanoma (20-22). Fingolimod (FTY720), an immune-suppressive drug developed by chemical modification of myriocin and a metabolite of the fungus Isaria sinclairii $(23,24)$, is phosphorylated by SK1 and SK2 (23). Phosphorylated FTY720 (FTY720-P) is a structural analogue of S1P and binds to four $\mathrm{S} 1 \mathrm{P}$ receptor subtypes $\left(\mathrm{S}_{1} \mathrm{P}_{1}, \mathrm{~S}_{1} \mathrm{P}_{3}, \mathrm{~S}_{1} \mathrm{P}_{4}\right.$, and $\left.\mathrm{S}_{1} \mathrm{P}_{5}\right)(25)$. 
However, persistent activation of $\mathrm{S}_{1} \mathrm{P}_{1}$ by FTY720-P causes its internalization and degradation, thereby acting as a functional antagonist in lymphocytes (26). FTY720 also induces apoptosis in melanoma $(27,28)$, liver cancer (16), and breast cancer (29) by direct inhibition of SK1 (29). FTY720 has predominantly been used for the treatment of multiple sclerosis (30). Recent in vitro and in vivo studies have shown that it is cytotoxic and efficiently reduced the viability of ovarian (31), breast (32) and prostate (33) cancer cells.

We previously reported that combination treatment with cisplatin and FTY720 has synergistic effects on apoptosis induction in cisplatin-resistant melanoma cells (34). Therefore, in this study we investigated the combined effects of FTY720 and vemurafenib in established vemurafenib-resistant melanoma cells, as well as the underlying molecular mechanisms.

\section{Materials and methods}

Chemical reagents. FTY720 was obtained from Cayman Chemical (Ann Arbor, MI, USA). Vemurafenib, bovine serum albumin (BSA), Dulbecco's modified Eagle's medium (DMEM), and Eagle's minimal essential medium (EMEM) were purchased from Wako Pure Chemical Industries (Osaka, Japan). RPMI-1640, non-essential amino acids (NEAA), and dimethylsulfoxide (DMSO) were obtained from Sigma-Aldrich; Merck KGaA (Darmstadt, Germany). Rabbit polyclonal antibodies against SK1, p53, cleaved poly (adenosine diphosphate-ribose) polymerase (PARP), PI3K, phosphorylated PI3K (p-PI3K), Akt, p-Akt, MEK, p-MEK, ERK, p-ERK, S6 kinase (S6 K), mammalian target of rapamycin (mTOR), p-mTOR, epidermal growth factor receptor (EGFR), and p-EGFR were obtained from Cell Signaling Technology, Inc. (Danvers, MA, USA).

Cell lines and cell viability measurement. Human melanoma SK-Mel-28 cells were obtained from JCRB Cell Bank (Osaka, Japan), and human melanoma cell lines (A375, A2058, WM115) were purchased from the European Collection of Cell Cultures. SK-Mel-28 and WM115 cells were cultured in RPMI-1640 containing 10\% foetal bovine serum (FBS) and $0.1 \%$ tyrosine. A375 cells were cultured in DMEM containing $10 \%$ FBS. A2058 cells were grown in EMEM containing $1 \%$ NEAA and $10 \%$ FBS. To assess viability, melanoma cells were plated at a density of $5 \times 10^{3}$ cells/well in 96 -well plates, and after $24 \mathrm{~h}$ vemurafenib and/or $3 \mu \mathrm{M}$ FTY720 were added to the medium. Viability was analysed after $24,48,72$ and $96 \mathrm{~h}$ using the standard 3-(4,5-dimethylthiazol-2-yl)-2,5-diphenyl-tetrazoliudm bromide (MTT) assay, where viable cells with active metabolism, but not dead cells, convert MTT into the corresponding purple-coloured formazan. We found the most effective time to be $72 \mathrm{~h}$ on vemurafenib in melanoma cells. When the determination of 50\% inhibitory concentrations $\left(\mathrm{IC}_{50}\right)$ for vemurafenib was performed in a 96 -well plate, vemurafenib was added to the cells at concentrations from 1 to $15 \mu \mathrm{M}$ for $72 \mathrm{~h}$ in the presence or absence of $3 \mu \mathrm{M}$ FTY720. Cells treated with DMSO only were used as a control, and $\mathrm{IC}_{50}$ values were calculated.

To prepare vemurafenib-resistant cells, SK-Mel-28 cells were repeatedly exposed to high doses of vemurafenib over a

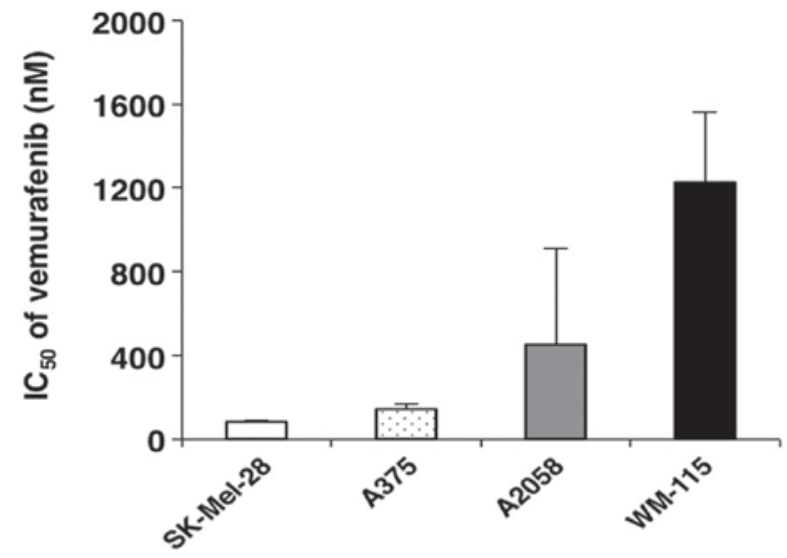

Figure 1. Comparison of the sensitivity to vemurafenib in various melanoma cells. Four melanoma cell lines $\left(1 \times 10^{4}\right.$ cells/well $)$ were incubated with various concentrations of vemurafenib for $72 \mathrm{~h}$, and MTT assays were performed. Each condition was measured in triplicate, and $\mathrm{IC}_{50}$ values were calculated. The data are expressed as the mean \pm standard deviation of three independent experiments. $\mathrm{IC}_{50}, 50 \%$ inhibitory concentrations; MTT, 3-(4,5-dimethylthiazol-2-yl)-2,5-diphenyl-tetrazoliudm bromide.

period of 10 months as described by Stordal et al (35). When the cell cultures had undergone approximately five doublings in the presence of $10 \mu \mathrm{M}$ vemurafenib, the proliferating cells were collected and transferred to drug-free culture conditions for recovery and MTT assay was then performed. The treatment was repeated at doses of $10 \mu \mathrm{M}$ vemurafenib for 10 months and the most resistant clone, R-SK-Mel, was selected. R-SK-Mel cells were grown in DMEM medium supplemented with $10 \mu \mathrm{M}$ vemurafenib, and before each experiment, the resistant cells were cultured in the absence of the target drug for $24 \mathrm{~h}$.

Western blot analysis. Cells were lysed by sonication in RIPA buffer [50 mM Tris-HCL buffer ( $\mathrm{pH}$ 7.6), $150 \mathrm{mM}$ $\mathrm{NaCl}, 1 \%(\mathrm{w} / \mathrm{v}) \mathrm{NP}-40,0.5 \%(\mathrm{w} / \mathrm{v})$ sodium deoxycholate, protease inhibitor cocktail, and $0.1 \%$ (w/v) sodium dodecyl sulfate (SDS)]. Total cell lysates (5 $\mu \mathrm{g}$ protein) were separated by electrophoresis on 7.5-10\% SDS-polyacrylamide gels and transferred to polyvinylidene difluoride membranes (EMD Millipore, Billerica, MA, USA). The membranes were blocked in 5\% BSA. Expression of each protein was measured by western blotting with each antibody. Anti- $\beta$-actin antibody was used as the loading control. After several washes, bound antibodies were detected using the ECL western blotting detection system (Luminescent Image Analyzer LAS-4000; Fujifilm, Tokyo, Japan). Protein band density was determined with a densitometer (Multi gauge, version 3.1; Fujifilm).

Statistical analysis. Data are expressed as the mean \pm standard deviation. Microsoft Excel (Microsoft Corp., Redmond, WA, USA) was used to calculate the correlation index. The statistical significance was analysed by either Student's t-test or one-way factorial analysis of variance with Fisher's protected least significant difference post hoc test for multiple comparisons, using EZR version 1.35 software (Saitama Medical Center, Jichi Medical University, Saitama, Japan). P $<0.05$ was considered to indicate a statistically significant difference. 

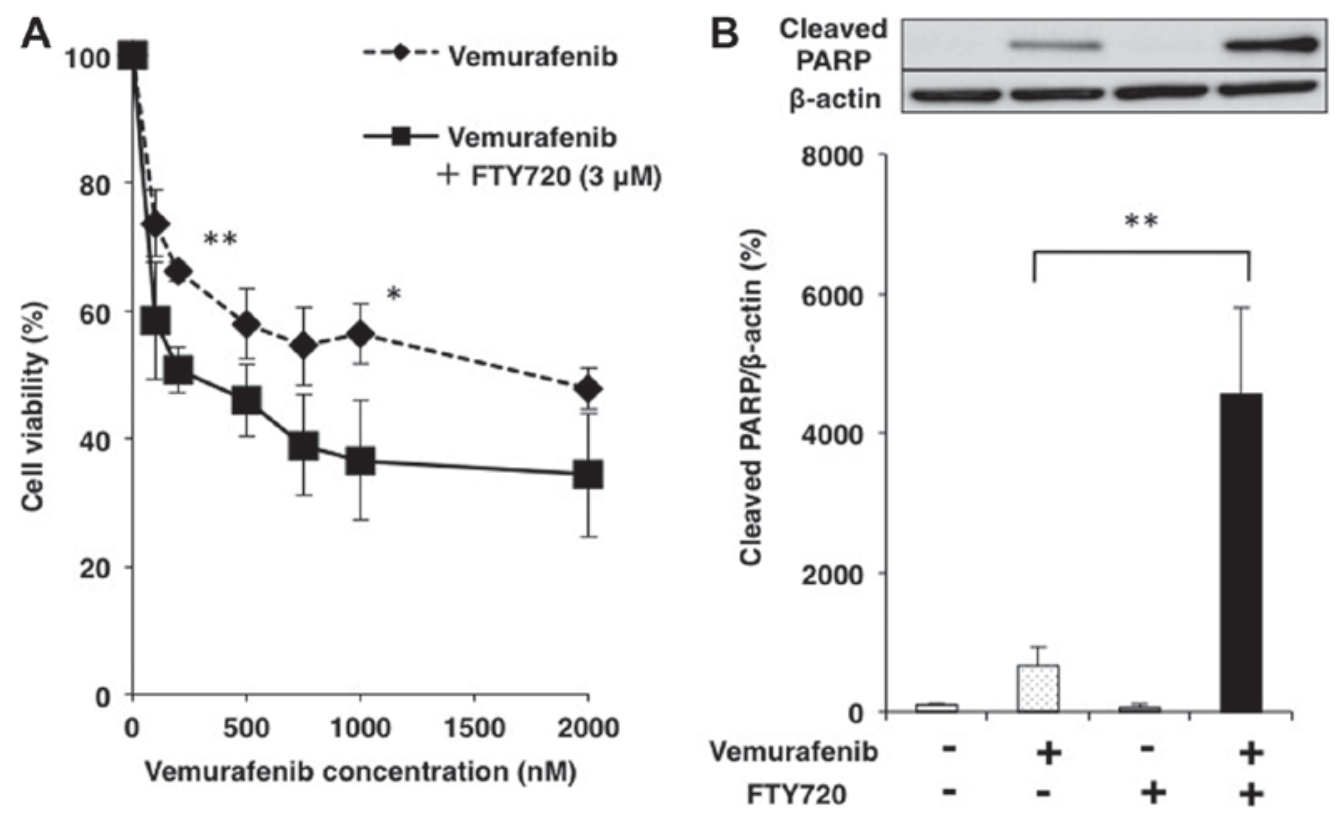

Figure 2. (A) The effects of FTY720 on the viability of WM-115 cells. WM-115 cells ( $1 \times 10^{4}$ cells/well) were incubated with various concentrations of vemurafenib in the presence or absence of $3 \mu \mathrm{M}$ FTY720 for $72 \mathrm{~h}$, then MTT assays were performed. Each condition was measured in triplicate, and the data are expressed as the mean \pm standard deviation of three independent experiments. ${ }^{*} \mathrm{P}<0.05$ and ${ }^{* *} \mathrm{P}<0.01$ vs. vemurafenib+FTY720 at the corresponding concentration. (B) The effects of FTY720 on the apoptosis of WM-115 cells. WM-115 cells were treated with $3 \mu$ M FTY720 and $2 \mu$ M vemurafenib, alone or in combination for $48 \mathrm{~h}$. Cell lysates were subjected to western blot analysis with an antibody against cleaved PARP, and the band intensity was measured. The results are expressed as a percentage increase relative to the untreated controls. The data are expressed as the mean \pm standard deviation. ${ }^{* *} \mathrm{P}<0.01$, as indicated. FTY720, fingolimod; PARP, poly (adenosine diphosphate-ribose) polymerase; MTT, 3-(4,5-dimethylthiazol-2-yl)-2,5-diphenyl-tetrazoliudm bromide.

\section{Results}

Sensitivity of various melanoma cells to vemurafenib. To examine the sensitivity of four melanoma cell lines (SK-Mel-28, A375, A2058 and WM-115) to vemurafenib, cell viability was measured after a $72 \mathrm{~h}$ incubation with vemurafenib. The $\mathrm{IC}_{50}$ for vemurafenib was highest in WM-115 cells and lowest in SK-Mel-28 cells (Fig. 1). The relative $\mathrm{IC}_{50}$ values for vemurafenib in SK-Mel-28, A375, A2058 and WM-115 cells were $82 \pm 9.19,145 \pm 24.7,452 \pm 46.1$ and $1227 \pm 336$, respectively. Therefore, WM-115 and SK-Mel-28 cells were used in subsequent experiments as vemurafenib-resistant and vemurafenib-sensitive cell lines, respectively.

Synergistic effects of FTY 720 and vemurafenib combination treatment on apoptosis in vemurafenib-resistant cells. To evaluate the effects of FTY720 on WM-115 cell viability, we compared the viability of cells treated with vemurafenib alone and the combination of vemurafenib and FTY720. The $\mathrm{IC}_{50}$ of treatment with vemurafenib alone was reduced by approximately $75 \%$ in the presence of $3 \mu \mathrm{M}$ FTY720 (Fig. 2A). FTY720 alone at $3 \mu \mathrm{M}$ had no significant effects on viability (data not shown). These results suggest that the addition of FTY720 to vemurafenib significantly reduced viability compared to treatment with vemurafenib alone in resistant WM-115 cells. The effects of FTY720 and vemurafenib on the apoptosis of WM-115 cells were examined using western blotting to measure the amount of PARP protein degradation, a marker of apoptosis. In WM-115 cells, cleaved PARP protein was expressed by $2 \mu \mathrm{M}$ vemurafenib alone, but not by $3 \mu \mathrm{M}$ FTY720 alone (Fig. 2B). However, the combination treatment with $2 \mu \mathrm{M}$ vemurafenib and $3 \mu \mathrm{M}$ FTY720 induced a synergistic increase in PARP degradation (Fig. 2B). These results showed that the addition of FTY720 to vemurafenib enhanced apoptosis compared with vemurafenib alone in WM-115 cells.

Changes in the expression of proteins in cell signaling pathways and SKI by combination treatment with vemurafenib and FTY720 in vemurafenib-resistant cells. The effects of combination treatment with $2 \mu \mathrm{M}$ vemurafenib and $3 \mu \mathrm{M}$ FTY720 on MEK and ERK phosphorylation in WM-115 were evaluated by western blot analysis. The ratio of phosphorylated to total MEK (p-MEK/t-MEK) was decreased by combination treatment, but the difference was not significant (Fig. 3A). In contrast, the ratio of phosphorylated to total ERK (p-ERK/t-ERK) was remarkably decreased by combination treatment compared with vemurafenib alone ( $\mathrm{P}<0.01$; Fig. 3B). We investigated the changes in the ratio of phosphorylated to total Akt (p-Akt/t-Akt) after the treatment with $2 \mu \mathrm{M}$ vemurafenib, $3 \mu \mathrm{M}$ FTY720 or both agents in WM-115 cells.

The treatment with $2 \mu \mathrm{M}$ vemurafenib or $3 \mu \mathrm{M}$ FTY720 alone induced no significant changes in Akt protein expression (Fig. 4A). Conversely, the treatment with combined FTY720 and vemurafenib caused a synergistic decrease in t-Akt protein expression (Fig. 4A), whereas there were no significant changes in p-Akt/t-Akt (Fig. 4B).

The effects of the combination treatment on SK1 with $2 \mu \mathrm{M}$ vemurafenib and $3 \mu \mathrm{M}$ FTY720 was evaluated by western blotting. The expression of SK1 was significantly decreased with combination treatment compared with vemurafenib treatment alone (Fig. 4C).

Establishing vemurafenib-resistant $R$-SK-Mel cells and evaluating changes in the expression of cell signaling 

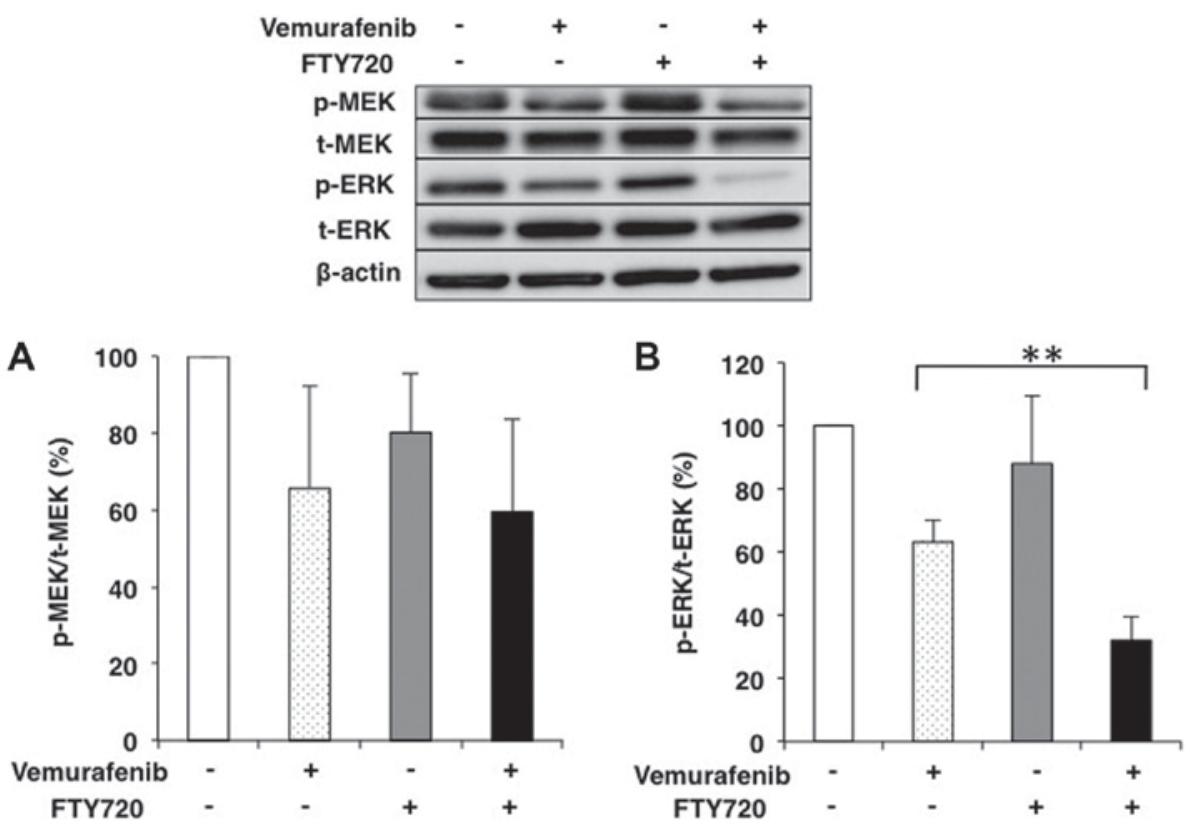

Figure 3. The effects of FTY720 and vemurafenib on the expression of (A) MEK and (B) ERK in WM-115 cells. WM- 115 cells were treated with $3 \mu$ M FTY720 and $2 \mu \mathrm{M}$ vemurafenib, alone or in combination for $48 \mathrm{~h}$. Cell lysates were subjected to western blot analysis with antibodies against the total (t) and phosphorylated (p) forms of (A) MEK and (B) ERK. The ratios of phosphorylated to total MEK and ERK were calculated. $\beta$-actin was used as the loading control. The results are expressed as the ratios of treated to untreated cells. Each condition was examined in triplicate, and the data are expressed as the means \pm standard deviation. ${ }^{* *} \mathrm{P}<0.01$, as indicated. FTY720, fingolimod; MEK, mitogen-activated protein kinase kinase; ERK, extracellular signal-related kinase; p-, phosphorylated; t-, total.

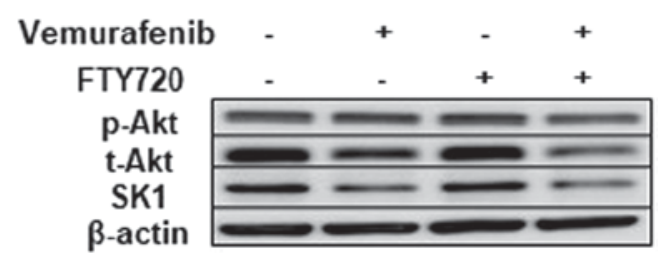

A

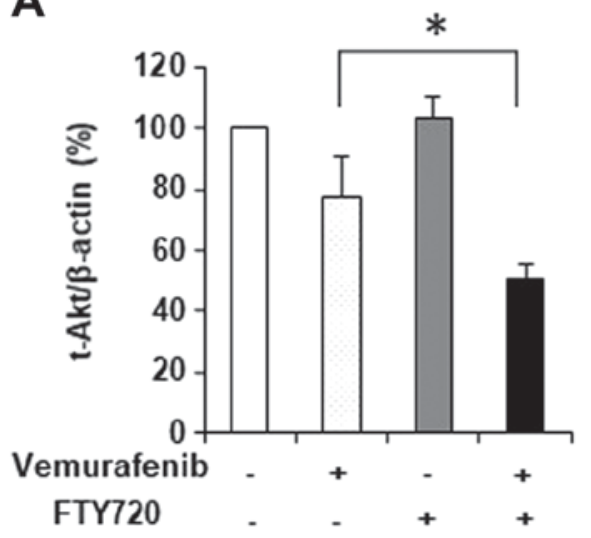

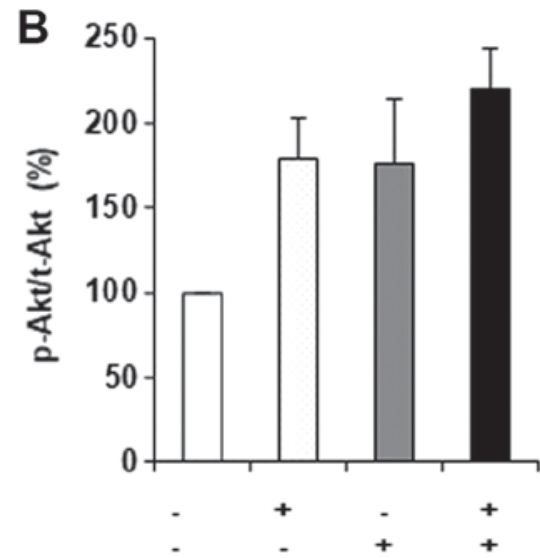

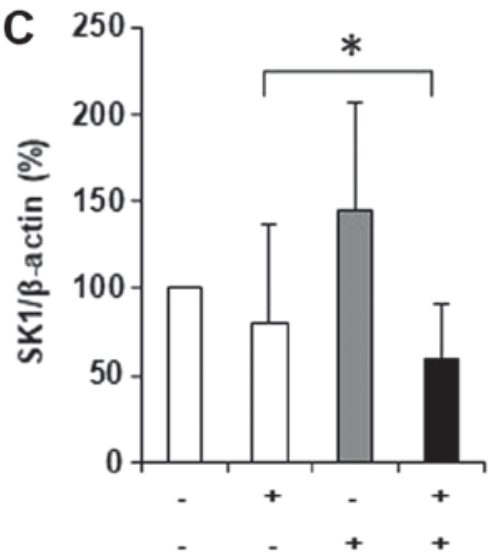

Figure 4. Effects of FTY720 and vemurafenib on the protein expression of (A and B) Akt and (C) SK1 in WM-115 cells. WM-115 cells were treated with $3 \mu \mathrm{M}$ of FTY720 and $2 \mu \mathrm{M}$ vemurafenib, alone or in combination, for $48 \mathrm{~h}$, and cell lysates were subjected to western blot analysis with antibodies against the total forms of (A) Akt and (C) SK1, and against the total (t) and phosphorylated (p) forms of (B) Akt. $\beta$-actin was used as the loading control. The results are expressed as ratios of treated to untreated cells. Each condition was examined in triplicate, and data are expressed as the means \pm standard deviation. "P<0.05, as indicated. FTY720, fingolimod; Akt, protein kinase B; SK1, sphingosine kinase 1; p-, phosphorylated; t-, total.

proteins in these cells. To confirm the role of signalling proteins in the sensitivity to vemurafenib and FTY720, we attempted preparation of the vemurafenib-resistant cell line by treating the original vemurafenib-sensitive SK-Mel-28 cells with a high concentration of vemurafenib as described in the Materials and Methods. Consequently, we succeeded in establishing the vemurafenib-resistant cell line R-SK-Mel, which can proliferate even in the presence of $10 \mu \mathrm{M}$ vemurafenib. As shown in Fig. $5 \mathrm{~A}$, the $\mathrm{IC}_{50}$ of vemurafenib in R-SK-Mel cells was 50-fold higher than that in the parent 

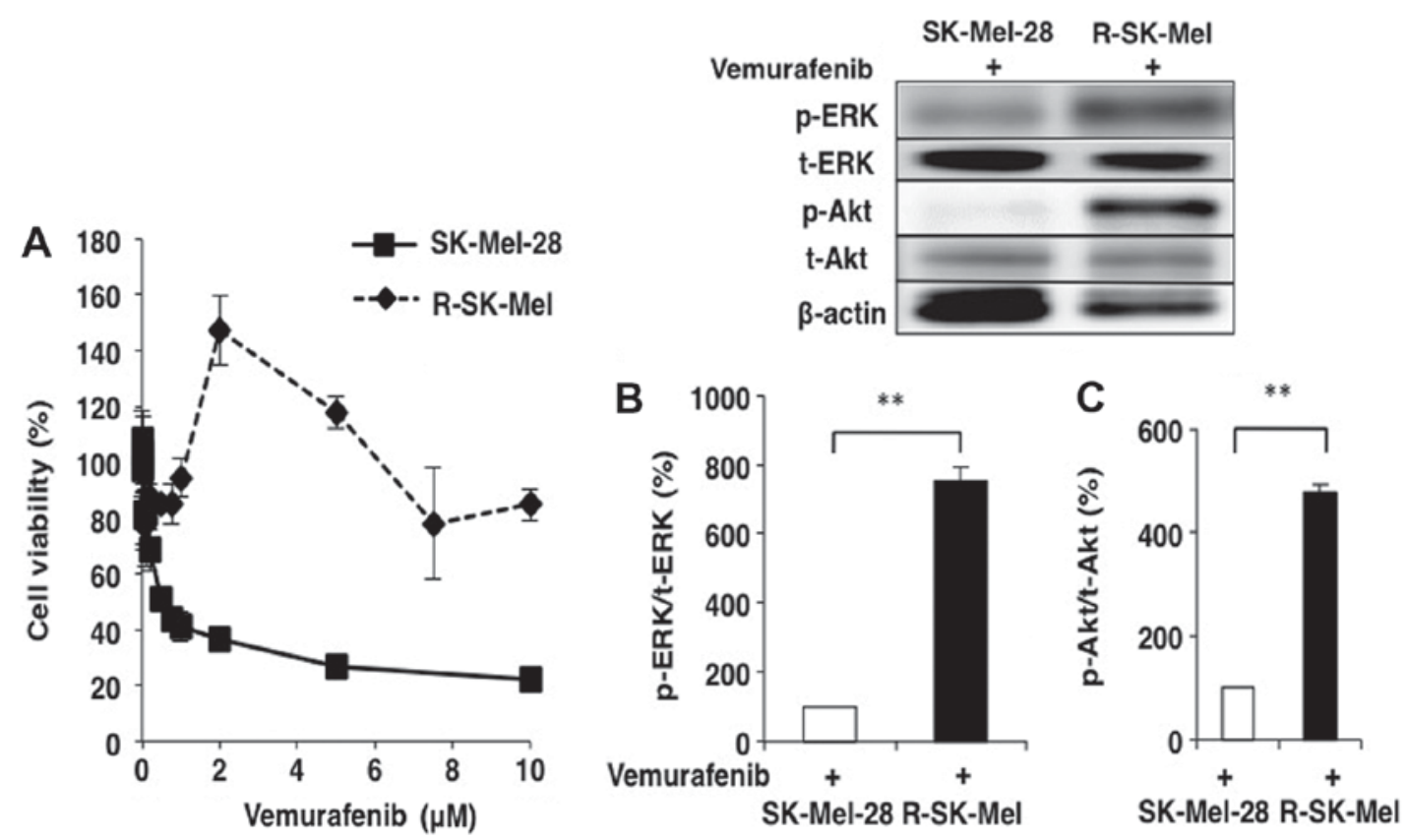

Figure 5. (A) The effects of vemurafenib on the viability of SK-Mel-28 and R-SK-Mel cells. SK-Mel-28 and R-SK-Mel cells (1x10 ${ }^{4}$ cells/well) were incubated with various concentrations of vemurafenib for $72 \mathrm{~h}$, then MTT assays were performed. Each condition was measured in triplicate, and the data are expressed as the mean \pm standard deviation of three independent experiments. Comparisons of the expression of (B) ERK and (C) Akt in SK-Mel-28 and R-SK-Mel cells. SK-Mel-28 and R-SK-Mel cells were treated with $2 \mu \mathrm{M}$ vemurafenib for $48 \mathrm{~h}$. Cell lysates were subjected to western blot analysis with antibodies against total (t) and phosphorylated (p) forms of (B) ERK and (C) Akt. The ratios of phosphorylated to total ERK and Akt were calculated. $\beta$-actin was used as the loading control. The results are expressed as a percentage increase relative to the ratio of SK-Mel-28 cells. Each condition was examined in triplicate, and the data are expressed as the means \pm standard deviation. ${ }^{* *} \mathrm{P}<0.01$, as indicated. R-SK-Mel, SK-Mel-28 resistant; ERK, extracellular signal-related kinase; Akt, protein kinase B; p-, phosphorylated; t-, total.

cell line. Changes in the expression of cell signaling proteins was examined between the parent and resistant cells. The expression levels of $\mathrm{p}$-ERK/t-ERK and $\mathrm{p}$-Akt/t-Akt were remarkably increased in R-SK-Mel cells compared with those in parent SK-Mel-28 cells treated with $2 \mu \mathrm{M}$ vemurafenib (Fig. 5B and C).

Synergistic effects of FTY 720 and/or vemurafenib combination treatment on cell viability and apoptosis in $R$-SK-Mel cells. We used MTT assays to compare the cell viability of SK-Mel-28 and R-SK-Mel cells treated with FTY720. The $\mathrm{IC}_{50}$ of vemurafenib in R-SK-Mel cells was remarkably reduced by treatment with FTY720 compared with that in SK-Mel-28 cells (Fig. 6A). The effects of FTY720 and vemurafenib combination treatment on R-SK-Mel cell apoptosis were evaluated using western blotting to measure the expression of cleaved PARP. In R-SK-Mel cells, only combination treatment with $10 \mu \mathrm{M}$ vemurafenib and $10 \mu \mathrm{M}$ FTY720 induced a synergistic increase in PARP degradation (Fig. 6B).

Changes in the expression of $p$-ERK/t-ERK and p-Akt/t-Akt by combination treatment with vemurafenib and FTY720 in $R$-SK-Mel cells. Changes in the expression of proteins in the MAPK and PI3K-Akt signalling pathways upon combination treatment with $10 \mu \mathrm{M}$ vemurafenib and $10 \mu \mathrm{M}$ FTY720 in R-SK-Mel cells were investigated. The expression levels of p-ERK/t-ERK and p-Akt/t-Akt were remarkably decreased by combination treatment (Fig. 7A and B). However, p-MEK/ t-MEK expression did not significantly change with this combination treatment (Fig. 7C).

\section{Discussion}

The MAPK and PI3K-Akt pathways are major pathways underlying cancer development and progression (36), and the latter pathway is particularly important for cell survival in melanoma (37). Several studies have previously described the mechanism of resistance to BRAF inhibitors, and noted that acquisition of the activated NRAS mutation (38) leads to reactivation of the MAPK pathway. Furthermore, there have been many reports on the mechanisms underlying resistance to BRAF inhibitors such as activation of receptor tyrosine kinase (39), increased expression of mutated BRAF kinase, increased expression of Cancer Osaka Thyroid (40), acquisition of MAP2K1 mutations (41) and loss of NF1 (42).

In this study, we demonstrated that the melanoma cell line WM-115 was most resistant to the BRAF inhibitor (vemurafenib), and exhibited much higher expression levels of p-ERK compared with vemurafenib-sensitive cells (data not shown). Furthermore, when changes in the expression of cell signaling molecules in R-SK-Mel cells were compared with the parent cells, we found that the levels of p-ERK and p-AKT were remarkably increased in R-SK-Mel cells, suggesting that both the MAPK and PI3K-Akt pathways were enhanced in the vemurafenib resistant-melanoma cells.

We also examined the effects of FTY720 and vemurafenib combination treatment on the resistant cells. This treatment strongly reduced cell viability, and also induced a synergistic increase in cleaved PARP in the vemurafenib-resistant WM-115 and R-SK-Mel cells. These results suggested that the addition of FTY720 to vemurafenib was effective in enhancing apoptosis 
A

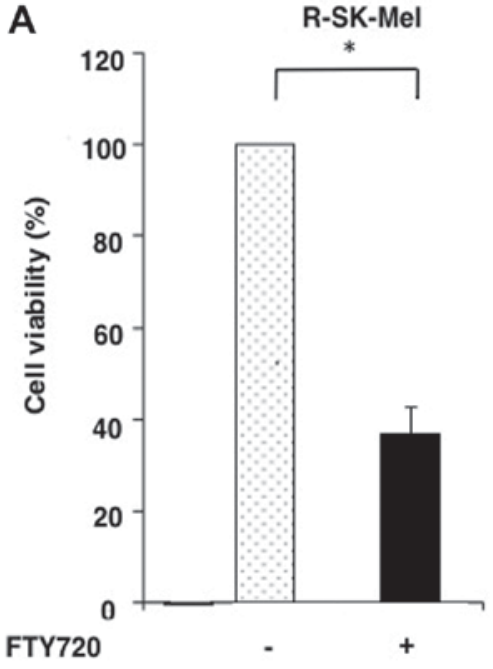

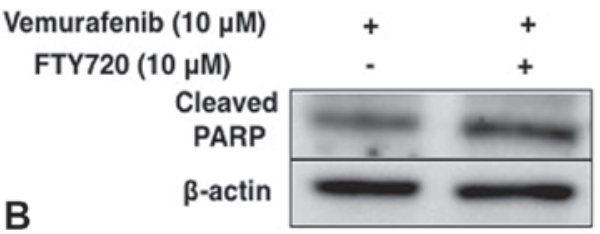

B

$\beta$-actin

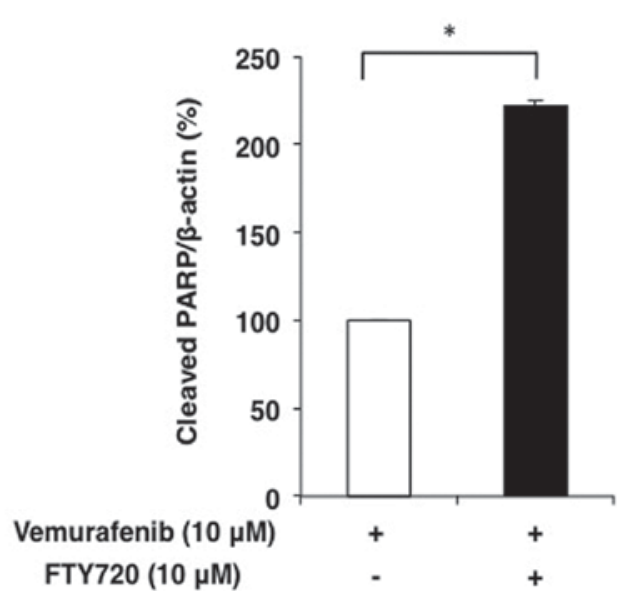

Figure 6. (A) The effects of FTY720 on the viability of R-SK-Mel cells. R-SK-Mel cells ( $1 \times 10^{4}$ cells/well) were incubated without or with $10 \mu \mathrm{M}$ of FTY720 for $72 \mathrm{~h}$, then MTT assays were performed. Each condition was measured in triplicate, and the data are expressed as the mean \pm standard deviation of three independent experiments. (B) The effects of FTY720 on the apoptosis of vemurafenib-resistant R-SK-Mel cells. Vemurafenib-resistant R-SK-Mel cells were treated with $10 \mu \mathrm{M}$ vemurafenib with or without $10 \mu \mathrm{M}$ FTY720. Cell lysates were subjected to western blot analysis with antibodies against cleaved PARP, and the band intensity was measured. $\beta$-actin was used as the loading control. The results are expressed as a percentage increase relative to the treatment without FTY720. The data are expressed as the means \pm standard deviation. " $\mathrm{P}<0.05$, as indicated. FTY720, fingolimod; R-SK-Mel, SK-Mel-28 resistant; PARP, poly (adenosine diphosphate-ribose) polymerase.
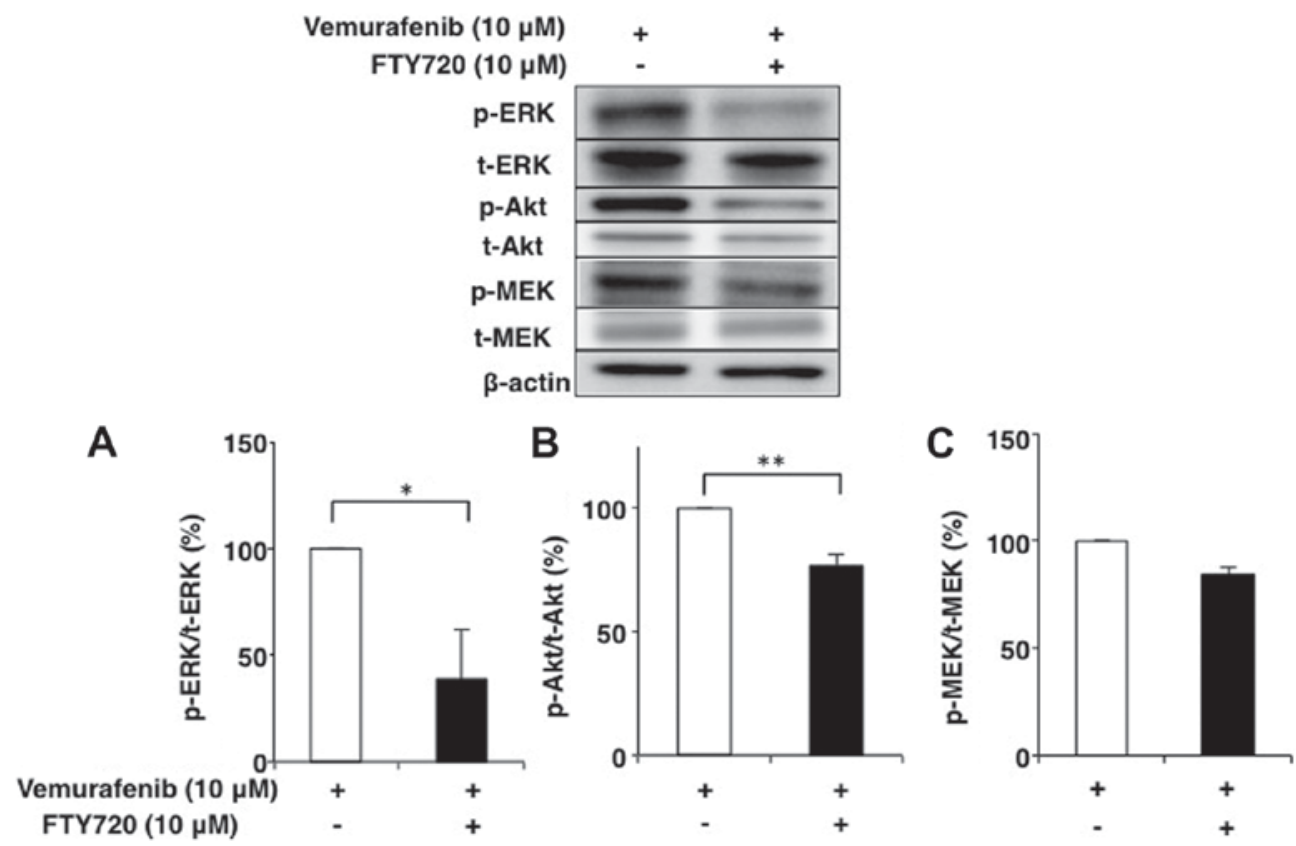

Figure 7. Effects of FTY720 on the expression of (A) ERK, (B) Akt and (C) MEK in vemurafenib-resistant R-SK-Mel cells. Vemurafenib-resistant R-SK-Mel cells were treated with $10 \mu \mathrm{M}$ vemurafenib with or without $10 \mu \mathrm{M}$ FTY720 for $48 \mathrm{~h}$. Cell lysates were subjected to western blot analysis with antibodies against total (t) and phosphorylated (p) forms of (A) ERK, (B) Akt and (C) MEK. The ratios of phosphorylated to total ERK, Akt and MEK were calculated. $\beta$-actin was used as the loading control. The results are expressed as a percentage relative to the treatment without FTY720. The data are expressed as the mean \pm standard deviation. " $\mathrm{P}<0.05$ and ${ }^{* *} \mathrm{P}<0.01$, as indicated. FTY720, fingolimod; R-SK-Mel, SK-Mel-28 resistant; MEK, mitogen-activated protein kinase kinase; ERK, extracellular signal-related kinase; Akt, protein kinase B; p-, phosphorylated; t-, total.

compared with vemurafenib treatment alone. Furthermore, we also examined the change in protein expression in cell signaling pathway components by this combination treatment in the resistant cells. In the MAPK pathway, p-ERK/t-ERK, and t-Akt 
and SK1 were remarkably decreased by this treatment, whereas there was no significant change in $\mathrm{p}-\mathrm{MEK} / \mathrm{t}-\mathrm{MEK}$. Moreover, this combination treatment induced remarkable decreases in the levels of p-ERK/t-ERK and also p-Akt/t-Akt in R-SK-Mel cells.

We previously reported that the combination treatment with cisplatin and FTY720 had synergistic effects on apoptosis induction in cisplatin-resistant melanoma cells by SK1 degradation, possibly due to downregulation of the PI3K/Akt/mTOR pathway via the S1P receptor and reduced EGFR expression (34). In addition, FTY720 mediates many anticancer effects through inactivation of the PI3K/Akt pathway mediated via a variety of mechanisms including the inhibition of PI3K, increased PTEN expression, activation of protein phosphatase 2A activity and SK1 inhibition (43). In accordance with these studies, our results strongly suggest that the combination treatment with FTY720 and vemurafenib induces apoptosis by downregulating both PI3K/Akt and MAPK pathways in melanoma cells.

Recently, several cases of malignant melanoma have been documented in patients with multiple sclerosis who were being treated with FTY720 (44-46), and a relationship between treatment by FTY720 and occurrence of melanoma has been suggested. However, since the exact mechanism of the relationship has not been elucidated, we believe that further studies are necessary. Furthermore, we strongly suggest that FTY720 is most effective as combination treatment with anticancer drugs rather than as treatment by itself in clinical applications.

This combination treatment in vemurafenib-resistant melanoma cells did not induce significant changes in $\mathrm{p}-\mathrm{MEK} / \mathrm{t}-\mathrm{MEK}$ expression. A recent study demonstrated that another pathway is activated by BRAF mutation, which directly activates ERK through Abl and Arg activation, but not through MEK (47). The authors also indicated that Abl/Arg cooperates with a parallel, compensatory signalling pathway (PTEN loss/Akt activation) to promote melanoma growth and survival. Based on this report, FTY720 likely plays a major role in inhibiting Akt activity, which consequently enhances cell apoptosis. The latest therapy for patients affected by BRAF mutated melanoma is a combination therapy of BRAF inhibitor and MEK inhibitor. Our data suggest that more effective pharmacodynamic actions can be obtained by using FTY720, which may block signalling pathways via ERK, but not via MEK, as well as the Akt pathway.

The results of this study suggest that FTY720 may be an effective agent for enhancing antineoplastic effects and apoptosis, and thus, decreasing resistance to vemurafenib in patients being treated with this agent.

\section{Acknowledgements}

Not applicable.

\section{Funding}

No funding was received.

\section{Availability of data and materials}

The datasets used and/or analysed during the current study are available from the corresponding author on reasonable request.

\section{Authors' contributions}

TT, HK, YB and MS conceived and designed the study. TT, NA and YB performed the experiments. TT, YB and MS wrote the paper. All authors have read and approved the final manuscript.

\section{Ethics approval and consent to participate}

Not applicable.

\section{Patient consent for publication}

Not applicable.

\section{Competing interests}

The authors declare that they have no competing interests.

\section{References}

1. Davies H, Bignell GR, Cox C, Stephens P, Edkins S, Clegg S, Teaque J, Woffendin H, Garnett MJ, Bottomley W, et al: Mutations of the BRAF gene in human cancer. Nature 417: 949-954, 2002.

2. Lovly CM, Dahlman KB, Fohn LE, Su Z, Dias-Santagata D, Hicks DJ, Hucks D, Berry E, Terry C, Duke M, et al: Routine multiplex mutational profiling of melanomas enables enrollment in genotype-driven therapeutic trials. PLoS One 7: e35309, 2012.

3. Jakob JA, Bassett RL Jr, Ng CS, Curry JL, Joseph RW, Alvarado GC, Rohlfs ML, Richard J, Gershenwald JE, Kim KB, et al: NRAS mutation status is an independent prognostic factor in metastatic melanoma. Cancer 118: 4014-4023, 2012.

4. Gray-Schopfer VC, Karasarides M, Hayward R and Marais R: Tumor necrosis factor- $\alpha$ blockes apoptosis in melanoma cells when BRAF signaling is inhibited. Cancer Res 67: 122-129, 2007.

5. Chapman PB, Hauschild A, Robert C, Haanen JB, Ascierto P, Larkin J, Dummer R, Garbe C, Testori A, Testori A, et al: Improved survival with vemurafenib in melanoma with BRAF V600E mutation. N Eng J Med 364: 2507-2516, 2011.

6. Hauschild A, Grob JJ, Demidov LV, Jouary T, Gutzmer R, Millward M, Rutkowski P, Blank CU, Miller WH Jr, Kaempgen E, et al: Dabrafenib in BRAF-mutated metastatic melanoma: A multicentre, open-label, phase 3 randomised controlled trial. Lancet 380: 358-365, 2012.

7. Lito P, Rosen N and Solit DB: Tumor adaptation and resistance to RAF inhibitors. Nat Med 21: 1401-1409, 2013.

8. Falchook GS, Lewis KD, Infante JR, Gordon MS, Vogelzang NJ, DeMarini DJ, Sun P, Moy C, Szabo SA, Roadcap LT, et al: Activity of the oral MEK inhibitor trametinib in patients with advanced melanoma: A phase 1 dose-escalation trial. Lancet Oncol 13: 782-789, 2012.

9. Shimizu T, Tolcher AW, Papadopoulos KP, Beeram M, Rasco DW, Smith LS, Gunn S, Smetzer L, Mays TA, Kaiser B, et al: The clinical effect of the dual-targeting strategy involving $\mathrm{PI} 3 \mathrm{~K} / \mathrm{AKT} / \mathrm{mTOR}$ and RAS/MEK/ERK pathways in patients with advanced cancer. Clin Cancer Res 18: 2316-2325, 2012.

10. Taha TA, Hannun YA and Obeid LM: Sphingosine kinase: Biochemical and cellular regulation and role in disease. J Biochem Mol Biol 39: 113-131, 2006.

11. Ogretmen B and Hannun YA: Biologically active sphingolipids in cancer pathogenesis and treatment. Nat Rev Cancer 4: 604-616, 2004.

12. Olivera A, Kohama T, Edsall L, Nava V, Cuvillier O, Poulton S and Spiegel S: Sphingosine kinase expression increases intracellular sphingosine-1-phosphate and promotes cell growth and survival. J Cell Biol 147: 545-558, 1999.

13. Xia P, Wang L, Gamble JR and Vadas MA: Activation of sphingosine kinase by tumor necrosis factor-alpha inhibits apoptosis in human endothelial cells. J Biol Chem 274: 34499-34505, 1999.

14. Spiegel S and Milstien S: Sphingosine-1-phosphate: An enigmatic signalling lipid. Nat Rev Mol Cell Biol 4: 397-407, 2003. 
15. Xia P, Gamble JR, Wang L, Pitson SM, Moretti PA, Wattenberg BW, D'Andrea RJ and Vedas MA: An oncogenic role of sphingosine kinase. Curr Biol 10: 1527-1530, 2000.

16. Ho JW, Man K, Sun CK, Lee TK, Poon RT and Fan ST: Effects of a novel immunomodulating agent, FTY720, on tumor growth and angiogenesis in hepatocellular carcinoma. Mol Cancer Ther 4: 1430-1438, 2005.

17. Pchejetski D, Doumerc N, Golzio M, Naymark M, Teissié J, Kohama T, Waxman J, Malavaud $\mathrm{B}$ and Cuvillier $\mathrm{O}$ : Chemosensitizing effects of sphingosine kinase-1 inhibition in prostate cancer cell and animal models. Mol Cancer Ther 7: 1836-1845, 2008.

18. French KJ, Schrecengost RS, Lee BD, Zhuang Y, Smith SN, Eberly JL, Yun JK and Smith CD: Discovery and evaluation of inhibitors of human sphingosine kinase. Cancer Res 63: 5962-5969, 2003.

19. Shida D, Takabe K, Kapitonov D, Milstien S and Spiegel S: Targeting SphK1 as a new strategy against cancer. Curr Drug Targets 9: 662-673, 2008.

20. Vadas M, Xia P, McCaughan G and Gamble J: The role of sphingosine kinase 1 in cancer: Oncogene or non-oncogene addiction? Biochim Biophys Acta 1781: 442-447, 2008.

21. Azuma H, Takahara S, Horie S, Muto S, Otsuki Y and Katsuoka Y: Induction of apoptosis in human bladder cancer cells in vitro and in vivo caused by FTY720 treatment. J Urol 169: 2372-2377, 2003.

22. Ubai T, Azuma H, Kotake $Y$, Inamoto T, Takahara K, Ito Y, Kiyama S, Sakamoto T, Horie S, Muto S, et al: FTY720 induced $\mathrm{Bcl}$-associated and Fas-independent apoptosis in human renal cancer cells in vitro and significantly reduced in vivo tumor growth in mouse xenograft. Anticancer Res 27: 75-88, 2007.

23. Billich A, Bornancin F, Dévay P, Mechtcheriakova D, Urtz N and Baumruker T: Phosphorylation of the immunomodulatory drug FTY720 by sphingosine kinases. J Biol Chem 278: 47408-47415, 2003.

24. Paugh SW, Payne SG, Barbour SE, Milstien S and Spiegel S: The immunosuppressant FTY720 is phosphorylated by sphingosine kinase type2. FEBS Lett 554: 189-193, 2003

25. Wang JD, Takahara S, Nonomura N, Ichimaru N, Toki K, Azuma H, Matsumiya K, Okuyama A and Suzuki S: Early induction of apoptosis in androgen-independent prostate cancer cell line by FTY720 requires caspase-3 activation. Prostate 40: 50-55, 1999.

26. Matloubian M, Lo CG, Cinamon G, Lesneski MJ, Xu Y, Brinkmann V, Allende ML, Proia RL and Cyster JG: Lymphocyte egress from thymus and peripheral lymphoid organs is dependent on S1P receptor 1. Nature 427: 355-360, 2004.

27. Pereira FV, Arruda DC, Figueiredo CR, Massaoka MH, Matsuo AL, Bueno V and Rodrigues EG: FTY720 induces apoptosis in B16F10-NEX2 murine melanoma cells, limits metastatic development in vivo, and modulates the immune system. Clinics (Sao Paulo) 68: 1018-1027, 2013.

28. LaMontagne K, Littlewood-Evans A, Schnell C, O'Reilly T, Wyder L, Sanchez T, Probst B, Butler J, Wood A, Liau G, et al: Antagonism of sphingosine-1-phosphate receptors by FTY720 inhibits angiogenesis and tumor vascularization. Cancer Res 66: 221-231, 2006

29. Tonelli F, Lim KG, Loveridge C, Long J, Pitson SM, Tigyi G, Bittman R, Pyne S and Pyne NJ: FTY720 and (S)-FTY720 vinylphosphonate inhibit sphingosine kinase 1 and promote its proteasomal degradation in human pulmonary artery smooth muscle, breast cancer and androgen-independent prostate cancer cells. Cell Signal 22: 1536-1542, 2010.

30. Kihara Y, Maceyka M, Spiegel S and Chun J: Lysophospholipid receptor nomenclature review: IUPHAR review $8 . \mathrm{Br} J$ Pharmacol 171: 3575-3594, 2014.

31. Zhang N, Qi Y, Wadham C, Wang L, Warren A, Di W and Xia P: FTY720 induces necrotic cell death and autophagy in ovarian cancer cells: A protective role of autophagy. Autophagy 6: $1157-1167,2010$
32. Azuma H, Takahara S, Ichimaru N, Wang JD, Itoh Y, Otsuki Y, Morimoto J, Fukui R, Hoshiga M, Ishihara T, et al: Marked prevention of tumor growth and metastasis by a novel immunosuppressive agent, FTY720, in mouse breast cancer models. Cancer Res 62: 1410-1419, 2002.

33. Chua CW, Lee DT, Ling MT, Zhou C, Man K, Ho J, Chan FL, Wang X and Wong YC: FTY720, a fungus metabolite, inhibits in vivo growth of andorogen-independent prostate cancer. Int J Cancer 117: 1039-1048, 2005

34. Ishitsuka A, Fujine E, Mizutani Y, Tawada C, Kanoh H, Banno Y and Seishima M: FTY720 and cisplatin synergistically induce cell death of cisplatin-resistant melanoma cells through downregulation of PI3K pathway and decrease in epidermal growth factor receptor expression. Int J Mol Med 34: 1169-1174, 2014.

35. Stordal BK, Davey MW and Davey RA: Oxaliplatin induces drug resistance more rapidly than cisplatin in H69 small cell lung cancer cells. Cancer Chemother Pharmacol 58: 256-265, 2006.

36. Meier F, Schittek B, Busch S, Garbe C, Smalley K, Satyamoorthy K, Li G and Herlyn M: The RAS/RAF/MEK/ERK and PI3K/AKT signaling pathways present molecular targets for the effective treatment of advanced melanoma. Front Biosci 10: 2986-3001, 2005.

37. Sinnberg T, Lasithiotakis K, Niessner H, Schittek B, Flaherty KT, Kulms D, Maczey E, Campos M, Gogel J, Garbe C and Meier F: Inhibition of PI3K-AKT-mTOR signaling sensitizes melanoma cells to cisplatin and temozolomide. J Invest Dematol 129: 1500-1515, 2009.

38. Nazarian R, Shi H, Wang Q, Kong X, Koya RC, Lee H, Chen Z, Lee MK, Attar N, Sazegar H, et al: Melanoma acquire resistance to B-RAF (V600E) inhibition by RTK or N-RAS upregulation. Nature 468: 973-977, 2010

39. Villanueva J, Vultur A, Lee JT, Somasundaram R, Fukunaga-Kalabis M, Cipolla AK, Wubbenhorst B, Xu X, Gimotty PA, Kee D, et al: Acquired resistance to BRAF inhibitors mediated by a RAF kinase switch in melanoma can be overcome by cotargeting MEK and IGF-1R/PI3K. Cancer Cell 18: 683-695, 2010.

40. Johannessen CM, Boehm JS, Kim SY, Thomas SR, Wardwell L, Johnson LA, Emery CM, Stransky N, Cogdill AP, Barretina J, et al: COT drives resistance to RAF inhibition through MAP kinase pathway reactivation. Nature 468: 968-972, 2010.

41. Emery CM, Vijayendran KG, Zipser MC, Sawyer AM, Niu L, Kim JJ, Hatton C, Chapra R, Oberholzer PA, Karpova MB, et al: MEK1 mutations confer resistance to MEK and B-RAF inhibition. Proc Natl Acad Sci USA 106: 20411-20416, 2009.

42. Hodis E, Watson IR, Kryukov GV, Arold ST, Imielinski M, Theurillat JP, Nickerson E, Auclair D, Li L, Place C, et al: A landscape of driver mutations in melanoma. Cell 150: 251-263, 2012.

43. Patmanathan SN, Yap LF, Murray PG and Paterson IC: The antineoplastic properties of FTY720: Evidence for the repurposing of fingolimod. J Cell Mol Med 19: 2329-2340, 2015.

44. Filoni A, Lospalluti L, Giudice G, Bonamonte D and Vestita M: Fingolimod and melanoma risk: Is there sufficient evidence? Clin Exp Dermatol 42: 427-428, 2017.

45. Haebich G, Mughal A and Tofazzal N: Superficial spreading malignant melanoma in a patiet on fingolimod therapy for multiple sclerosis. Clin Exp Dermatol 41: 433-434, 2016.

46. Conzett KB, Kolm I, Jelcic I, Kamarachev J, Dummer R, Braun R, French LE, Linnebank M and Hofbauer GF: Melanoma occurring during treatment with fingolimod for multiple sclerosis: a case report. Arch Dermatol 147: 991-992, 2011.

47. Jain A, Tripathi R, Turpin CP, Wanq C and Pattner R: Abl kinase regulation by BRAF/ERK and cooporation with Akt in melanoma. Oncogene 36: 4585-4596, 2017. 